\title{
Response to Ch'i and Artistic Expression: An East Asian Worldview that Fits the Creative Process Everywhere, Shaun McNiff
}

\author{
回应Shaun McNiff \\ 的《“气” 和艺术性表达 : 契合所有创造性过程的东 \\ 亚世界观》 \\ Sharon Davis Brown \\ Art of Business Coaching, USA
}

\begin{abstract}
Ch'i, described by McNiff as a material force, vital energy, or breath, is a concept that easily translates into the dance/movement therapy lexicon. Ch'i as a conceptual concept may be applied in therapeutic settings, as a functional construct, and as an energy force. The use of these three applications, when combined with contemplative practices to achieve healing and harmony within oneself, can broaden into creative energy (innovation and collaboration).
\end{abstract}

Keywords: Ch’i; In therapy; Functional ch’i; Cultural perceptions; Contemplative practices

\section{摘要}

McNiff将 “气” 描述为一种物质力量、生命能量，或呼吸，是一个很容易转化为舞蹈/ 动作治疗词汇的概念。“气” 的概念性能够作为功能性结构和一种能量，应用于治疗之 中。这三种应用结合冥想练习，能够实现自我疗愈与和谐，可以扩大到创造力 ( 创新与 合作）。

\section{关键词：气，在治疗中，功能性的气，文化视角，冥想练习}

McNiff's description of ch'i as a material force, vital energy, or breath (McNiff, 2016) reminds me that the concept of $c h$ 'i easily translates into the dance/movement therapy lexicon. Clients bring their energies to dance/movement therapy sessions. This energy is described by Rudolf Laban as antrieb, a German phrase, which translates into English as on drive or the energy of making oneself known (Bartenieff, with Lewis, 1980). The term is further qualified by Laban to mean effort, a person's inner urge to move. We humans are in perpetual motion, with the breath (ch’i) maintaining the constant energy of life. This breath ceases to exist when life ends. Dance/movement therapists use this concept of breath or ch'i when we conduct therapeutic movement groups and as a functional construct in our day-to-day lives. 


\section{Ch'i in Therapy}

During therapy sessions, the dance/movement therapist's first task is to sense the energy of the group members. When working with children, the therapist may use a combination of fast and slow activities to create exertion and recuperation to help balance their energy. When working with frail elderly people, the therapist may use an upbeat rhythmic quality in the music and movement to bring a sense of vitality into the client's lives. Working with chronically mentally ill people, the therapist may use music and movement (gesture, posture, and breath) to allow the clients to sense their muscles and/or connect with another person in a non-invasive manner. This structure may bring an isolated client from their inner world to engagement with the outer world. Ch'i is a constant presence in the therapeutic space, and even if we do not overtly describe ch'i to our clients, they are able, through breath (ch'i) and movement, to facilitate the connection between the body and mind.

\section{Functional Ch'i}

Sometimes our days seem to linger with indulgence, whereas during other days, we find ourselves rushing to complete many urgent tasks. We are constantly pulled between inner and outer forces, both consciously and subconsciously. When we are stressed, there is a tendency to hold our breath and tighten our muscles. When we are relaxed, breath has an even flow and the muscles are flexible, giving a sense of well-being (Iyengar,1966). An awareness of our ch'i may renew our homeostasis. Functional $c h$ 'i is the way we monitor our attention to self and apply an energetic force in our everyday life.

$C h$ ' $i$ as a functional construct encourages people to bring harmony into their daily lives. This can be achieved through contemplative practices such as tai chi, yoga (Iyengar, 1966), aikido (Warneka, 2006), karate, and many forms of dance (social, folk, contact improvisation, authentic movement, waltz, tango, trance, hip hop, etc.). Harmony can be achieved through meditation or mindfulness practices, whereby the polarities of our inner urges (hunger, thirst, fatigue, and procreation) and our outer awareness (of our environment or being socially connected to others at work or in our families) begin to merge. Harmony can be achieved through the collective practice of singing or chanting together. This harmony-like formation helps facilitate healing, balance, and flexibility in our daily lives.

\section{Cultural Perceptions of $\mathrm{Ch}^{\prime} \mathbf{i}$}

There are differing culturally derived opinions about how energy is perceived. In Western culture, working ten to twelve-hour days in an organizational environment is often perceived as positive. However, people who take the time for self-fulfillment or self-care may discover increased satisfaction in the perceived significance of their day-to-day routine. However, critics of this ideology note the focus on self rather than the collective whole.

From an Eastern perspective, yoga activity engages ch'i by regulating the breath (pranayama) and by regulating muscles through steady, comfortable postures (asana) 
(Iyengar, 1966). In Chinese medicine (acupuncture), the acupuncturist takes a person's pulse to measure the energy $c h$ ' $i$ in the patient and structures their treatment plan based on this assessment and among other factors (Kaptchuk, 1983). A more structured, regulated ch'i is generally viewed as the objective. People practice tai chi to bring balance, health benefits, and meditation into their lives.

\section{Summary}

Ch'i as an energy force surrounds us, lives through us, and permeates all living things. It can be measured, controlled, or soothed. $C h$ 'i as a life force may be harnessed through contemplative practices to achieve healing and harmony within oneself that can broaden into creative energy (innovation and collaboration). Creative energy is the backbone of a successful organizational vision, one that can be achieved in western and eastern cultures despite differing cultural organizational ideologies.

\section{About the Author}

Sharon Davis Brown founded the Art of Business Coaching (ABC) to provide executive, business, and embodied leadership coaching to enhance individual and team dynamics. Her coaching work focuses on embodied leadership, decision-making, and building rapport and cooperation in business settings.

Her credentials include an MA and a PhD in human and organizational systems from Fielding Graduate University. She has an additional MA in expressive therapies with a specialization in dance/movement therapy from Lesley University. She is a certified movement analyst and a certified evidence-based coach (Fielding Graduate University).

\section{References}

Bartenieff, I., with Lewis, D. (1980). Body movement: Coping with the environment. Gordon and Breach. New York, NY

Iyengar, B.K.S. (1966). Light on yoga. Schocken Books. New York, NY

Kaptchuk, T. (1983). The web has no weaver: Understanding Chinese medicine. Congdon \& Weed. New York, NY

McNiff, S. (2016). Ch'i and artistic expression: an East Asian worldview that fits the creative process everywhere. Creative Arts in Education and Therapy, 2(2), 12-20.

Warneka, T. (2006). Leading people the black belt way: Conquering the five core problems facing leaders today. Asogomi Publishing.Cleveland, $\mathrm{OH}$ 